\title{
REFLEXÕES SOBRE AS IDENTIDADES-CONSUMO NA AMÉRICA LATINA SOBRE A ÓTICA DA ATIVIDADE TURÍSTICA
}

\author{
Denio Santos Azevedo ${ }^{1}$ \\ Taís Antunes Paes ${ }^{2}$ \\ Polyana Bittencourt Andrade ${ }^{3}$
}

\section{RESUMO}

A atividade turística relaciona-se, diante da sua complexidade, com elementos midiáticos que estimulam o consumo de determinados destinos e culturas. Os planejadores turísticos transformaram e continuam transformando cidades, a história, a memória e o patrimônio cultural material e imaterial de grupos sociais específicos, entendidos como elementos representativos das identidades, em atrativos turísticos, ou seja, em objetos de consumo. Tal fabricação possui como base de sustentação o planejamento turístico e a sua difusão se dá a partir das diferentes mídias utilizadas na promoção turística. Consumir as identidades-consumo é consumir simbolicamente o "outro" e tal prática gera "distinção" entre os grupos sociais, constrói imaginários e alimenta a "concorrência "inter-cidades" no mercado latino dos deslocamentos programados para fins turísticos. Neste sentido, os planejadores turísticos motivam os deslocamentos temporários por meio da possibilidade destes viajantes terem contato com outras culturas e conhecimentos, por meio do consumo simbólico dos elementos identitários do "outro". É por meio do consumo simbólicos das representações identitárias de grupos sociais específicos que o turista ou visitante passa a identificar cidades e/ou países na promoção turística dos destinos. Considerando tais aspectos o presente estudo visa desenvolver reflexões sobre a relação entre o turismo, o turista e as identidades-consumo a partir de algumas observações sobre a promoção turística de algumas cidades latinas em sites de turismo aqui pesquisados. Observou-se, nos sites promocionais verificados, a representação de elementos considerados típicos de certos destinos turísticos como o Mariachi no México, a presença das comunidades guaranis na argentina, a exposição da gastronomia típica através dos Chivitos uruguaios, o Chorizo argentino, o Ceviche peruano, as Cachapas e as Arepas venezuelanas e as empanadas e o Charquicán do Chile, por exemplo. Entre os diversos aspectos identitários de uma localidade os planejadores turísticos acabam tornando representativos alguns deles passando a identificar as cidades e os seus residentes. Ciente de tais informações, o turista busca consumir "o que é do lugar".

Palavras-chave: Mídia. Turismo. Identidades-Consumo. América Latina.

\footnotetext{
${ }^{1}$ Doutor em Sociologia. Professor do Núcleo de Turismo da Universidade Federal de Sergipe. Coordenador do Projeto de Pesquisa Turismo e Identidaes-Consumo: construções e usos dos atrativos turísticos na formação dos imaginários das cidades (CNPq/UFS).

${ }^{2}$ Mestre em Administração. Professora do Núcleo de Turismo da UFS. Coordenadora do Projeto de Pesquisa Percepção ética dos gestores do setor turístico considerando as suas decisões gerenciais na cidade de Aracaju/SE.

${ }^{3}$ Mestre em Ciências Sociais. Professora do Curso de Comunicação Social da UNIT.
} 


\section{ABSTRACT}

Tourist activity is related, in the face of complexity, with media elements that encourage the consumption of certain destinations and cultures. The tour planners transformed and continue to transform cities, history, memory and tangible and intangible cultural heritage of specific social groups, understood as representative elements of identities in tourist attractions like objects of consumption. Such as manufacturing base has support tourism planning and its diffusion occurs from the different media used in tourism promotion. Consuming identities is an symbolically consume of the "other" and this practice generates "distinction" between social groups, imaginary constructs and feeds the "competition" inter-city "in the Latin market movements programmed for tourism purposes. In this sense, tourism planners motivate temporary dislocations through the possibility of these travelers have contact with other cultures and knowledge by means of symbolic consumption of the identity elements of the "other". It is through the symbolic use of the identity representations of specific social groups that the tourist or the visitor shall identify cities and / or countries in promoting tourism destinations. Considering these aspects, the present study aims to develop reflections on the relationship between tourism, tourists and consumer identities from some remarks on tourism promotion of some Latin cities into tourism sites surveyed here. Was observed in promotional sites, the representation of elements considered typical of certain tourist destinations such as Mariachi in Mexico, the presence of Guaraní communities in the Argentina, exposing the typical gastronomy through Chivitos Uruguayans, Argentines Chorizo, the Ceviche Peruvians, the Cachapas and the Venezuelan Arepas and empanadas and charquicán Chile, for example. Between different identity aspects of a city tour planners end up making some representative going to identify the cities and their

residents. Knowing such information, the tourist seeks to consume "what is the place."

Keywords: Media. Tourism. Identities Consumption. Latin America. 


\section{Introdução}

Pesquisar e escrever sobre identidades em ciências sociais não é uma tarefa fácil. A morte de diversas teorias sobre o tema já foi anunciada quando algumas destas ainda estavam no ventre. Escolas de pensamento que buscam para si a paternidade, a única verdade ou a exclusividade nos estudos, existem algumas. Debates acalorados, variações no conceito, denominações distintas, segmentações, causalidades, processos identitários, os porquês, como ou os modos através dos quais os fenômenos identitários ocorrem são marcas características da bibliografia que versa sobre o assunto. Hall (2003, p. 8) afirma que o conceito de identidade nas ciências sociais é "demasiadamente complexo, muito pouco desenvolvido e muito pouco compreendido".

Na mídia, nas campanhas eleitorais, nas justificativas acadêmicas e nos projetos técnicos tanto a identidade quanto o patrimônio são por diversas vezes mal utilizados ou ressignificados em diversos exemplos. Ambos são justificativas para salvar comunidades, defender territórios, gerar conflitos, justificar intervenções urbanas, tombar e revitalizar o bens de natureza material, registrar os bens imateriais, caracterizar movimentos sociais e para manutenção da memória coletiva. Ao mesmo tempo em que significa para estes a mesma coisa que tradição, memória coletiva e cidadania.

Há um uso excessivo e diversificado do conceito de identidade na chamada "era da globalização" e da "pós-modernidade". Identidades fluídas, líquidas, móveis, polissêmicas, poliglotas, dinâmicas, em transição, híbridas, móveis, complexas e múltiplas apareceram no cenário acadêmico. Identidades enquanto resistência a uma generalização que se propagava com a globalização, sujeitos pósmodernos vivendo em harmonia com as suas múltiplas identidades, identidades que caracterizam, se classificam, preservam ou protegem grupos, classes, regiões e nações. Identidades que geram a diferença ou que se constroem a partir dela. "Desta forma, a identidade na modernidade tornou-se crescentemente problemática e o assunto da própria identidade tornou-se por si só um problema". (KELLNER, 2001, p. 143)

Interessante que até as duas primeiras décadas da segunda metade do século XX Bauman (2005, p. 23) afirma que a discussão sobre 
identidade "não estava nem perto do centro do nosso debate, permanecendo unicamente um objeto de meditação filosófica". Mas por que as identidades passaram a chamar tanta atenção dos pesquisadores nas ciências sociais a partir da globalização e da pósmodernidade?

Escosteguy (2001) ao abordar especificamente sobre o interesse dos Estudos Culturais em abordar o assunto nos traz algumas pistas, tais como: a desestabilização gerada pela modernidade; a tão propagada crise da modernidade e o processo de globalização. Hall (2003) nos fala da insegurança gerada por algumas certezas da modernidade, no descentramento dos sujeitos, na demanda por inclusão de grupos étnicos, a luta pelo reconhecimento da pluralidade e coloca sob "rasura" alguns conceitos-chaves para explicar este interesse no debate e nos novos olhares sobre o estudo das identidades. Bauman (2003) afirma que houve uma fragmentação do modelo de Estado-nação, desregulamentação dos processos econômicos e culturais e o surgimento dos sujeitos com "recursos e autoconfiança", desprendidos das amarras estabelecidas até então pelo modelo de comunidade dos Estados nacionais.

Especificamente neste estudo teórico percebe-se uma relação interessante entre as identidades e o consumo de atrativos turísticos nos mercados latinos. Elementos simbólicos de grupos sociais específicos passaram a identificar cidades e/ou países na promoção turística dos destinos. Imaginários são construídos e precisam ser ratificados ou retificados na concretização da viagem. Estes precisam motivar o deslocamento temporário de "estrangeiros" que estão movimentando o mercado de turismo em busca de encontros com as "diferentes", trocas culturais e do conhecimento, ou seja, do consumo simbólico dos elementos identitários do "outro". Desta forma, o objetivo central deste estudo é lançar um debate sobre a relação entre o turismo, o turista e as identidades-consumo a partir de algumas reflexões sobre a promoção turística das cidades latinas em sites de turismo aqui pesquisados. 


\title{
1. Turismo e Consumo
}

O desenvolvimento da tecnologia, a supervalorização da máquina, a produção em série, o lucro exacerbado, as mudanças nas relações de trabalho, a acumulação do capital, os salários, a competição e as classes econômicas passaram a ser determinantes na organização das relações sociais no mundo e, portanto com necessidades de pesquisas e entendimento sobre o complexo fenômeno do consumo.

As novas jornadas de trabalho, a importância do tempo dedicado ao descanso, aliado ao surgimento e desenvolvimento do transporte ferroviário, deram a oportunidade, por exemplo, para o planejamento e prática das primeiras viagens de grupos ainda no século XIX, com pacotes que incluíam transporte e serviços adicionais.

\begin{abstract}
A Revolução Industrial introduz, então, o tempo cronometrado estabelecendo o período de trabalho, induzindo assim [...], o tempo do não-trabalho, aquilo que hoje chamaríamos de lazer [...], vindo a constituir o turismo como prática social, vigente portanto dentro da sociedade industrial (CAMARGO, 2008, p.66).
\end{abstract}

No contexto da modernidade e das revoluções industriais, a atividade turística passou por transformações motivadas principalmente pelas tecnologias na indústria e no setor de transportes, aparecimento da burguesia no cenário socioeconômico, mudanças de mentalidade no mundo do trabalho e processo de urbanização acelerado. $\mathrm{O}$ mundo então passa a conhecer o turismo moderno, com necessidades de maior planejamento, infraestrutura e interação entre os setores de serviços utilizados no decorrer das viagens turísticas. No mundo contemporâneo uma das possibilidades de estudo sobre o turismo enquanto fenômeno social é entendê-lo com os óculos de uma cultura de consumo entre os grupos sociais.

Featherstone (1995) ao perceber que a "cultura consumo" é mais complexa que uma consequência imediata da produção apresenta três perspectivas sobre tal prática. A primeira leva em consideração o crescimento, desenvolvimento e solidificação do capitalismo, produção de mercadorias e consequente acúmulo de cultura material. "Isso resultou na proeminência cada vez maior do lazer e das atividades de consumo nas sociedades ocidentais contemporâneas" (FEATHERSTONE, 1995, p. 31). O lazer é uma das grandes motivações para o deslocamento, ou seja, este atrelado ao surgimento 
das férias representa fator central para o desenvolvimento da atividade turística no mundo.

Na perspectiva "mais estritamente sociológica" Featherstone (1995, p. 31) percebe a relação entre uso de mercadorias, inserção e afastamento de grupos sociais e distinções sociais. Nem todos consomem variados produtos. Os motivos são os mais distintos sendo a condição econômica, a necessidade e o uso da mercadoria os mais destacados. Por outro lado, as formas de consumo constroem relações sociais e demarcam posições sociais. Onde se consome e o quê se consome são questionamentos feitos cotidianamente para construir representações de atores sociais e grupos, numa leitura superficial, você é o que você consome e exibe. Ressaltar ainda que o que é consumido, ganha funções, usos e dimensões simbólicas diferenciadas por quem consome a partir de um contexto histórico, socioeconômico e cultural que impõe ao mesmo produto importância diferenciada.

Em um terceiro momento Featherstone (1995) destaca os prazeres construídos e saciados pelo consumo. $\mathrm{O}$ mercado deve a todo instante despertar no possível consumidor o gosto e a necessidade pelo consumo. Os sons, as fotografias, os vídeos, a publicidade, os bens simbólicos, o status, a variedade de mercadorias, as inovações, dentre outros desperta nos atores sociais o sonho e o desejo do consumo. $\mathrm{O}$ consumista é levado a lugares de consumo e a consumo de lugares. Estas práticas geram sensações tão prazerosas que somente àqueles que as fazem pode definir. "O capitalismo também produz (somos tentados a seguir a retórica pós-modernista e dizer 'superproduz') imagens e locais de consumo que endossam os prazeres do excesso" (FEATHERSTONE, 1995, p. 42).

A depender da articulação de sentidos que esses aspectos possam assumir em diferentes momentos históricos, poderá gerar "distinção" (BOURDIEU, 2007) entre os membros de grupos sociais. É uma espécie de mecanismo social e cultural que leva em consideração as práticas de consumo cultural como elemento de diferenciação de quem consome e do que é consumido. As segmentações do mercado turístico, as cidades, os atrativos turísticos consumidos, atrelado a um conjunto de sentidos atribuídos geram distinção entre os turistas.

Adaptando-se ao mercado na primeira década do século XXI, os planejadores turísticos brasileiros decidiram investir na denominada 
segmentação do turismo. Pensando contrariamente a proposta tão difundida em décadas passadas do turismo de massa, onde a busca pela quantidade de turistas, independente da motivação, era a principal disputa na "concorrência inter-cidades", definiram "tipos de turismo", surgindo então o turismo étnico, turismo cultural, turismo de experiência, turismo criativo, ecoturismo, dentre outros.

Os atores sociais que estão à frente do planejamento turístico traça um perfil de turista almejado a partir das pesquisas de demanda turística, dos seus atrativos, da infraestrutura existente, das atividades e práticas culturais, dos eventos, dos recursos naturais, do patrimônio cultural, dos meios de hospedagem, das práticas de lazer, dentre outros.

Com enfoque na demanda, a segmentação é definida pela identificação de certos grupos de consumidores caracterizados a partir das suas especificidades em relação a alguns fatores que determinam suas decisões, preferências e motivações, ou seja, a partir das características e das variáveis da demanda (MTUR/BRASIL, 2006, p. 3).

O modelo elaborado apesar de inovador na aparência consiste em leis de mercado e na tradicional máxima da oferta e da demanda. Várias cidades e/ou regiões passam a ser tematizadas a partir de planejamentos de marketing, narrativas e imagens elaboradas com o auxílio da publicidade, criando identidades e marcas características e específicas para os produtos comercializados nesses destinos segmentados turisticamente. Ressalta-se que em várias cidades, optouse por segmentações distintas em um mesmo destino, já em outras, a soma dos atrativos turísticos gerou uma segmentação regional.

Em todos os casos, recursos naturais e/ou grupos sociais identitários, juntamente com os bens e práticas culturais, passam a ser entendidos como atrativos turísticos, ou seja, mercadorias para consumo visual, sonoro, tátil ou simplesmente mercadológico. Percebe-se nos possíveis usos dessas segmentações a relação de atrativos turísticos que o caracterizam de acordo com as definições sugeridas pelos atores sociais que estão a frente do planejamento turístico e a relação sugerida de interesses que motivavam esses turistas ao deslocamento.

"Esse tipo de turismo pressupõe atividades que promovam a reflexão e a integração homem e ambiente, em uma inter-relação vivencial com o ecossistema, com os costumes e a história local" (MTUR/BRASIL, 2006, p. 10). O convívio, o contato com o "outro", os choques 
identitários, o consumo da natureza, a memória, os saberes/fazeres são elementos que compõem não só esse, como variados tipos de segmentação turística. Portanto, teoricamente, torna-se praticamente impossível diferenciar as possíveis práticas segmentadas da atividade turística.

No turismo cultural aquilo que é entendido como cultura pelos planejadores turísticos do Ministério do Turismo é o principal fator de deslocamento de turistas culturais. Ressalta-se que para alguns autores “todo turismo é cultural” (PORTUGUEZ, 2004; RICHARDS, 2009). Outra observação relevante é que nem toda prática de consumo cultural e de atividade turística cultural é feita, especificamente, por turistas culturais. No turismo cultural o patrimônio cultural é percebido como "fonte para a formatação de produtos turísticos singulares. A diversidade e a identidade cultural como fator de diferenciação para a oferta de atividades complementares e o posicionamento competitivo dos destinos e roteiros turísticos" (MTUR/BRASIL, 2010, p. 11). Aqui a busca pela diferenciação de outros destinos turísticos e a venda do único e exclusivo é pautada naquilo que o processo de patrimonialização definiu como herança cultural dos grupos sociais. A partir do posicionamento de instituições turísticas, percebe-se que patrimônio cultural, identidade e a diversidade cultural são construtores de imagens e imaginários dos destinos e mercadorias para consumo de turistas.

Com esse entendimento sobre cultura e com a inclusão do conceito de patrimônio cultural imaterial na América Latina, os atrativos representativos desse segmento deixaram de ficar limitados ao patrimônio cultural material tombado, aos museus, monumentos e aos chamados centros históricos. Há uma inclusão de novos atrativos turísticos que visa o contato com os grupos sociais no seu cotidiano, o consumo dos saberes/fazeres, das festas e celebrações, das formas de expressão, das feiras e de outros espaços onde são realizadas as mais variadas práticas dos mais diferentes atores sociais.

"Todos os atrativos culturais podem se transformar em produtos do Turismo Cultural” (MTUR/BRASIL, 2010, p.35). Cientes disso, os planejadores turísticos elaboram diagnósticos, procuram inventariar as práticas e os bens culturais que podem identificar os residentes e atrair turistas, inventam tradições, elaboram estratégias de marketing que vinculem os símbolos culturais escolhidos a imagem do destino 
turístico e o disponibilizam nas prateleiras do mercado turístico para o consumo.

As narrativas exigem planejamentos com a efetiva participação dos residentes, artistas, artesãos, brincantes dos grupos folclóricos e demais envolvidos. Almeja-se a interpretação patrimonial e o registro dessas práticas culturais. Aconselham-se práticas de educação patrimonial que sensibilizem os atores sociais para a importância da manutenção daquelas práticas para o desenvolvimento socioeconômico da comunidade, tendo como um dos agentes responsáveis por esse o turismo. O intuito é a realização da tríade "conhecer, valorizar, respeitar" que alimenta o planejamento turístico na sua relação com os residentes e inserção da comunidade como aliada na implementação e crescimento da atividade turística na localidade.

Reconhecendo-se no patrimônio cultural que se tornou atrativo turístico este ator social passa a ser uma fonte de informação para sanar as possíveis dúvidas dos visitantes turistas, é uma representação dessa construção identitária, entende o turismo como aliado na preservação do patrimônio e o turista como responsável pelo aumento da receita financeira na comunidade. Inseridos, os residentes também passam a ser entendidos pelos planejadores turísticos como mercadorias que passam a auxiliar na manutenção dos bens e práticas culturais.

As motivações do homem contemporâneo por experiências relacionadas a lugares e tempos diferentes do seu mundo cotidiano encontram inúmeras oportunidades junto às pequenas comunidades locais, onde a identidade cultural é um legado ancestral (MTUR/BRASIL, 2010, p. 61).

Os planejadores turísticos acreditam que podem e devem resgatar o que eles entendem como tradições que foram esquecidas pelos atores sociais, muitas vezes de forma sensível e consciente. Eles transformam as identidades culturais construídas em variados contextos históricos em identidade cultural do destino turístico. Em alguns casos esse movimento é inverso, essa identidade cultural é inventada, adaptada ou acrescentada representações simbólicas e/ou narrativas construídas por planejadores turísticos na elaboração de roteiros ou produtos turísticos.

[...] a identidade cultural do destino é cada vez mais capaz de diferenciá-lo e de torná-lo mais competitivo no mercado turístico, nacional ou internacional. Valorizando as histórias e a 
singularidade local, destinos turísticos podem oferecer uma oferta inovadora de produtos e serviços com carga emocional e que gerem experiências únicas, aplicando as atuais tendências do mercado turístico ao mercado do Turismo Cultural (MTUR/BRASIL, 2010, p. 63).

A busca pelo "autêntico", "original" e "tradicional" motiva o deslocamento de turistas que são induzidos a consumir o que é representativo das cidades e que identifica os seus residentes. Nos discursos midiáticos da promoção turística das cidades a um sentido de pertencimento entre os agentes sociais que residem nestas e o que está sendo ofertado enquanto atrativo turístico, principalmente quando é comercializado um bem registrado ou tombado pelas instituições responsáveis pelo patrimônio cultural. Tais bens culturais, entendidos como elementos representativos da herança cultural de grupos sociais específicos, passam a ser divulgados como elementos identitários de cidades ou nações e são transformados em atrativos turísticos para consumo.

\section{As Identidades-Consumo}

As identidades-consumo não podem ser percebidas como um conceito fechado, objetivo e estático. Este é complexo, dinâmico, marcado pela subjetividade e relações de poder. Elas são construídas a partir de um contexto, com fins específicos, vinculados diretamente ao seu objetivo central, o consumo. Tais construções são feitas por atores sociais que representam instituições públicas e/ou privadas e estão diretamente envolvidos com o mercado e o consumo de bens simbólicos. Planejadores turísticos de diversos segmentos do trade turístico, representantes das Secretarias Estaduais e Municipais de Cultura, empresários, publicitários, profissionais do marketing, técnicos vinculados às instituições oficiais do patrimônio cultural e líderes comunitários são os principais exemplos de construtores de identidades-consumo.

Estas não são feitas a partir de um vazio, mas com base em elementos de identificação dos residentes, já percebidos, analisados e selecionados ao longo da história. Cada um destes possui fins múltiplos, como por exemplo, a construção de identidades nacionais ou regionais e a seleção do patrimônio cultural ou natural. A função 
dos planejadores aqui destacados é repassar a população a necessidade de (re)conhecimento dos bens e práticas, auxiliar na manutenção e na divulgação do que o "sutura" a localidade. Outra forma de construção destas identidades-consumo se dá a partir das invenções, que também devem ser absorvidas pela comunidade local como pertencentes ao seu acervo cultural.

As identidades-consumo transformam as práticas e os bens culturais e naturais em mercadoria. Aliás, as invenções que são elaboradas para esse fim já nascem mercadoria. As festas, a gastronomia, o artesanato, as manifestações folclóricas, os centros históricos e o patrimônio natural que são identificados como locais, específicos, representativos de comunidades, comercializados como "autênticos" e "tradicionais" passam a potencializar estas adjetivações para atender aos interesses globais de consumo. Nas identidades-consumo em muitos casos há um investimento financeiro significativo para moldar os elementos às necessidades dos visitantes e nestes o valor cultural/natural dos bens se torna coadjuvante dos seus valores mercadológicos.

Nas duas dimensões do consumo, a material e cultural, consumir as identidades-consumo é consumir o "outro". Por exemplo, o artesanato é o resultado do saber/fazer de um grupo social ou de um determinado ator social que identifica a comunidade. Não adianta levar para casa qualquer objeto feito artesanalmente, mas aquele que é assinado pelo principal artista do destino turístico visitado ou que identifique de alguma forma a presença do turista na localidade, a partir de um selo por exemplo.

Os comerciantes visando um aumento do consumo acabaram abrindo espaço no mercado para a produção em série de bens que se querem representativos das cidades e dos seus residentes. Os "souvenires" homogeneizados são diferenciados com a simples menção de "lembrança da cidade". Os souvenirs são comercializados na maioria dos destinos turísticos do mundo. A presença de lojas e feiras livres comercializando objetos ditos "locais" para turistas, ávidos pela aquisição destas peças e motivados pelo apelo comercial do "típico", demonstra que existe uma "indústria de recordações" (SCHLÜTER, 1998). Na mercadorização dos bens culturais a produção em série procura fazer uma "cópia" da prática artesanal. Os turistas que buscam consumir as identidades-consumo podem ser levados a comprar tais produtos, 
desde que os mesmos entendam que ali é algo representativo da cidade e dos seus residentes.

O devorador das identidades-consumo, normalmente, procura nas cidades turísticas elementos e símbolos que possam saciar a sua sede e fome "antropofágicas". Ele procurar se encontrar nos lugares e somarse às experiências proporcionadas pelos residentes. Em determinado momento o "estrangeiro" pretende ser mais um na localidade. Ele não é um diferente distante, mas alguém que sabe que é diferente com possibilidades de trocas simbólicas e culturais com os "outros". O consumidor no encontro com as identidades-consumo estranha, compara, absorve, descarta, filtra, percebe o quanto é diferente, reconhece-se nas práticas e garante posições sociais distintas daqueles que não participaram do encontro.

As mercadorias representativas das identidades-consumo possuem funções diferenciadas para os seus consumidores. A gastronomia pode ser a responsável por saciar a necessidade fisiológica ou por ocupar um espaço vazio na necessidade de conhecimento de novos aromas, sabores e temperos característicos de grupos sociais. Uma panela de barro pode se tornar um objeto de decoração ou uma ferramenta necessária para elaborar pratos recomendados para ela. Independente dos seus usos, no ato da compra, ciente que é um elemento representativo das identidades-consumo, o estrangeiro está consumindo significações e sentidos produzidos pelo "outro" para ele. Com isso há um sentido cultural, econômico e simbólico no consumo.

Todavia, é importante destacar que, em muitos casos, o ato de consumir está relacionado a uma necessidade vinculada a posição social e autoestima. De acordo com Golçalves (2009) a partir do momento em que o comércio de identidades é percebido como um bom negócio, a sociedade de consumo, por meio de ações publicitárias, atribui aos seus produtos, de maneira cada vez mais sofisticada, o poder de satisfazer as aspirações identitárias dos consumidores sejam eles com elementos gastronômicos, sociais e culturais.

Diante de tais explanações é possível observar algumas percepções iniciais dos possíveis usos das identidades-consumo na América Latina. Boa parte dos elementos representativos aqui destacados são bens culturais registrados e que são reconhecidos como patrimônio 
cultural imaterial nacional ou até mesmo como patrimônio da humanidade. Portanto, estes são entendidos como elementos simbólicos que identificam os residentes em suas cidades, região ou país e são de fundamental importância para humanidade. Todos aqui citados são utilizados pelos planejadores do turismo como atrativos turísticos, ou seja, são também motivadores de deslocamento planejado de turistas.

Os saberes e os fazeres de índios e os seus remanescentes são consumidos em toda América Latina. Os mesmos são percebidos como grupos sociais "autênticos" deste recorte do mundo. Apenas conhecer tais atores sociais não interessa mais para uma parcela de turistas que percorre as cidades buscando um convívio temporário, que se inserem em seu cotidiano, dançam, cantam, celebram e se pintam como àqueles que os recebe.

Os guaranis foram os primeiros habitantes da terra missioneira.
Nas redondezas do Parque Nacional Iguaçu habitam
comunidades guaranis, sendo a Reserva M'Boboré uma das
mais importantes. Algumas comunidades abrem suas portas aos
visitantes e os recebem para compartilhar com eles uma jornada
onde é possível conhecer os aspectos de sua vida cotidiana e,
assim, sua cultura viva.
(http://www.argentina.travel/pt/xp/encontros-com-o-povo-
guarani)

Os turistas consomem gastronomia indígena, acompanham a elaboração de peças artesanais e escutam as histórias dos antepassados, a disputa por territórios, as dificuldades de manutenção das aldeias e a sensação de estarem diante da "tradição". É uma espécie de retorno as origens, a busca das bases culturais e étnicas de formação dos argentinos, por exemplo, no caso dos índios Guaranis.

No universo turístico o Mariachi está para o México assim como o Tango está para Argentina. "Ao redor do mundo, o mariachi é um símbolo reconhecido do México [...] Este é o som emblemático do México" (www.visitmexico.com). Acompanhado de toda importância que este representa para os mexicanos surge o convite para o turista ouvir, dançar e contemplar as apresentações dos diversos grupos de Mariachi espalhados pelo país assim como é com o Tango na Argentina. "A característica mais representativa da Argentina é a sua música: o tango. Ele se expressa como música instrumental, canção, dança e arte interpretativa dos argentinos". 
(www.mibuenosairesquerido.com). Nos materiais de promoção turística são listadas diversas tanguerias, que oferecem espetáculos artísticos, estruturadas especificamente para receber os turistas e que muitas vezes seguem a própria dinâmica da prática cultural, mas não deixa de ser "o tango argentino" nestas narrativas publicitárias.

No imaginário dos alimentos e bebidas representativos dos grupos sociais e das cidades latinas percebe-se no material pesquisado uma forte presença da cerveja em diversos países, os vinhos chilenos, argentinos, especialmente os produzidos com a uva Malbec e uruguaios, destacadamente os elaborados com a uva Tannat. O Pisco chileno, o Rum cubano, o Tereré paraguaio e a Tequila mexicana. São outros elementos representativos dos países aqui destacados

A diversidade cultural, formada pela miscigenação de diversos grupos étnicos, influencia de forma significativa na multiplicidade de aromas, temperos e sabores na gastronomia latina, mas no universo turístico apenas alguns destes variados elementos se tornam representativos e passam a identificar as cidades e os seus residentes. Os Chivitos uruguaios, o Chorizo argentino, o Ceviche peruano, as Cachapas e as Arepas venezuelanas, as empanadas e o Charquicán no Chile, o Chairo boliviano, o Chipás e o Locro no Paraguai, além da Bandeja Paisa colombiana. Na promoção turística de Cuba existe o que é denominado de "plato típico nacional", ou seja, "arroz, frijoles negros, ensalada de estación, carne de cerdo asada o al jugo y plátanos fritos". (http://www.cuba-travel.tur.cu/es/content/comida). Ciente de tais informações, o turista que busca consumir "o que é do lugar" não pode deixar de provar a gastronomia "típica" dos residentes, principalmente ciente que é um elemento representativo da cultura nacional.

Em vários países foram encontrados elementos representativos da gastronomia dos lugares com nomes e receitas semelhantes. O que é comum entre países tão próximos com processos de colonização semelhantes e intercâmbio cultural constante, mas que precisam ser diferenciados para auxiliar no despertar do interesse dos turistas que disputam a concorrência "inter-cidades". Imaginários são construídos e as estratégias estão lançadas, cabe ao turista interessado em consumir identidades escolher a cidade que mais lhe atrai e concretizar as suas experiências sensitivas, sonoras, visuais ou de qualquer outra ordem. Assim ocorre com outras práticas culturais como as festas. O carnaval é um exemplo de celebração comum a diversas localidades no mundo, 
mas os agentes que promovem o turismo na Colômbia afirmam em seu site oficial que:

O Carnaval de Barranquilla é único no mundo, por sua diversidade cultural e por ser uma festa onde todos somos protagonistas. é uma festa da Colômbia para o mundo. Uma festa mestiça de cumbias, pitos, mapalés, gaitas, chandés, puyas, fandangos e fantásticos merecumbés. É uma festa de "sones" e "danzones". Uma festa que recolhe tradições baseadas na criatividade de nossos povos expressada na dança, na música, nos artesanatos, nos disfarces e nas formas de festejar (COLÔMBIA TRAVEL, 2009).

Não há aqui uma afirmativa falsa ou uma tentativa de ludibriar os prováveis visitantes, já que toda e qualquer festa de carnaval é única em qualquer lugar do mundo. $O$ que existe são estratégias de marketing turístico que são globalizadas, perfis segmentados de turista e práticas de consumo de elementos culturais que são caracterizados como únicos, autênticos e representativos dos espaços que permitem o estudo da construção destas identidades-consumo no universo do turismo.

A relação entre turismo, identidade cultural e consumo se torna evidente nos eventos de independência das antigas colônias espanholas na América. $\mathrm{O}$ discurso de identidade nacional atrelado à celebração e a rememoração de práticas culturais representativas do Estado acaba atrelando um conjunto significativo de atrativos turísticos na promoção das cidades.

La más popular tradición chilena son las Fiestas Patrias cada 18 y 19 de septiembre, cuando se conmemora la Primera Junta de Gobierno de 1810. En fondas y ramadas, se disfruta con comidas típicas, empanadas, chicha y vino tinto, donde además se baila cueca y cumbia. Se cuelgan banderas, se elevan volantines y se hacen carreras a la chilena, con jinetes corriendo sin montura. (http://chile.travel/que-hacer/cultura-ypatrimonio/tradiciones-costumbristas-en-chile/)

Não é necessário aqui explicar profundamente as estratégias de construção dos Estados-Nação na América Latina ao longo das décadas ou até mesmo dos séculos. Dentre estas é possível destacar o estabelecimento de fronteiras, um mito de origem, a legitimação de uma língua oficial, a elaboração de uma história, geografia e literatura nacionais, a seleção de heróis nacionais e a confecção de uma cultura nacional. Vários destes elementos identitários povoam o imaginário turístico das cidades e precisam continuar a existir nos museus, nas 
praças, nas ruas, nas estátuas, nos centros históricos para alimentar um sentimento de pertencimento ao Estado e para atrair turistas que querem consumir o que é de mais simbólico e representativo do "outro".

Nos grandes eventos nacionais ou em festas "tradicionais" estes elementos representativos se encontram reunidos em espaços comuns, muitas vezes oriundos de diversas partes do Estado e completamente fora de contexto, mas fundamental para a prática da atividade turística. Sendo que, em muitos casos, o que importa é que o turista possa beber vinho tinto, comer empanadas, dançar Cumbia e apreciar as "tradicionais Constubristas", o rodeio chileno, ciente que está consumindo elementos identitários dos chilenos. Todas estas práticas são formas de inserção social, de entrelace e de sociabilidade que interessa aos planejadores turísticos, aos turistas que buscam tal consumo e que podem trazer tanto benefícios sociais e econômicos quanto um impacto cultural significativo para os residentes.

Não se acredita, nessa pesquisa, que isso ocorra de forma planejada, mas as identidades-consumo no universo do turismo auxiliam de alguma forma na construção de representações sociais fabricadas sobre a identidade latina. Tanto auxilia na manutenção quanto na transformação do latino no diálogo com outros construtores desse imaginário, o cinema, a música, as relações políticas estabelecidas, a imprensa, dentre outros.

\section{Considerações Finais}

As cidades na América Latina foram selecionando os bens culturais tombados e transformando-os em atrativos turísticos permitindo que estas cidades se tornassem turísticas. Na promoção turística, os bens patrimonializados passaram a ser representativos de cidades e residentes, com isso se tornaram diferenciais no processo de concorrência inter-cidades e deveriam motivar o deslocamento de turistas. Estes ao chegar aos destinos, buscariam formas diferenciadas de consumo.

Com isso, acredita-se que as narrativas que promovem turisticamente as cidades podem ser investigadas como artefatos culturais e sujeitas a 
explorações que revelem os sistemas de produção e significação que lhes dão origem a partir dos quais derivam o seu significado. Por trás de uma divulgação turística existe uma disputa por espaço e um conjunto de ações, motivações e valores de agentes sociais locais na construção de destinos turísticos.

A maneira como as pessoas compreendem e se empenham na construção destes imaginários dependerá de um contexto, de relações de poder, de um lugar e do tempo específico nesta construção. A imagem de uma cidade turística nunca é um objeto inerte e imutável. Os diferentes interessados (empreendedores, turistas, residentes, gestores) apropriam-se desta e contestam, criticam, indagam, acrescentam informações "esquecidas", lugares não contemplados. Esses atos, somados aos aqui já elencados fazem parte da maneira de como essas identidades são criadas e disputadas por atores sociais, grupos sociais ou cidades.

Tais construções do imaginário criam mitos locais, inventam tradições, elaboram uma ideia de patrimônio, autenticidade, originalidade, pregam uma harmonia com a natureza e fabricam identidadesconsumo. Essa promoção contribui para a produção cultural e o consumo de paisagens, espaços, lugares, "não-lugares", para atores sociais diferentes em tempos diferentes.

Percebe-se que esta é apenas uma das múltiplas possibilidades em representar as cidades e os seus residentes na América Latina. Os variados olhares que os residentes lançam sobre as cidades cotidianamente e a percepção que os turistas elaboram após a visita aos destinos são alguns exemplos das mais diferentes formas de imaginários das cidades e dos seus residentes.

As identidades das cidades latinas utilizadas pela promoção do turismo pode ser entendida como um dos exemplos das identidades-consumo. O consumo dos elementos representativos, de algo único, específico e/ou autêntico concede ao turista/consumidor uma distinção e uma sensação de consumo do "outro". Algo perseguido, almejado e desejado, por um grupo de turistas que quer jogar o jogo da experiência, da vivência e da experimentação. As identidades na promoção turística, são atrativos e diferenciais das cidades, e portanto, devem ser consumidas pelo turista. 
Em suma, os bens culturais tombados e registrados e os elementos representativos das identidades, criados por diversos atores sociais, em diferentes momentos históricos, foram transformados por gestores e planejadores turísticos em atrativos turísticos. Com a promoção turística, esses foram ainda os principais elementos construtores do imaginário turístico das cidades. Esse imaginário consegue despertar o desejo de deslocamento dos turistas para estas, que procuram de alguma forma ratificar ou retificar os imaginários construídos. Nesse momento, os elementos identitários são contemplados, vivenciados, comprados, fotografados, sentidos, experenciados, degustados, ou seja, são consumidos. Os elementos representativos dos latinos no turismo são transformados em exemplos de identidades-consumo que agregam valor aos recursos naturais, bens e práticas culturais que estão à disposição dos turistas nas prateleiras desse supermercado global do turismo.

\section{Referências}

BAUMAN, Zygmunt. Comunidade: a busca por segurança no mundo atual. Rio de Janeiro: Jorge Zahar, 2003.

. Identidade. Rio de Janeiro: Zahar, 2005.

BOURDIEU, Pierre. A Distinção: crítica social do julgamento. São Paulo: Edusp; Porto Alegre: Zouk, 2007.

BRASIL/MINISTÉRIO DO TURISMO. Turismo Cultural: orientações básicas. Brasília: MTUR, 2006.

BRASIL/MINISTÉRIO DO TURISMO. Segmentação do Turismo. Brasília: MTUR, 2010.

CAMARGO, Haroldo L. Fundamentos Multidisciplinares do Turismo: história. In: TRIGO, Luiz G. G. (org.), Turismo: como aprender, como ensinar - São Paulo: Editora Senac, 2008.

COLÔMBIA TRAVEL. 2009. Disponível em: <http://www.colombia.travel/po/turista-internacional/pontos-turisticosaonde-ir/barranquilla> 
ESCOSTEGUY, Ana Carolina. Cartografias dos estudos culturais: uma versão latino-americana. Belo Horizonte: Ed. Autêntica, 2001.

FEATHERSTONE, M. Cultura de Consumo e pós-modernismo. São Paulo: Studio Nobel, 1995.

GONÇALVES, Rafael. R. Identidade, consumo e sociabilidade: implicações éticas. Revista de Psicologia. v. 9, n. 1, 2009.

HALL, Stuart. Da Diáspora: identidades e mediações culturais. Liv Sovik (org). Belo Horizonte: Editora UFNG; Brasília: Representação da UNESCO no Brasil, 2003.

KELLNER, Douglas. A cultura da mídia: estudos culturais, identidade e política entre o moderno e o pós-moderno. Bauru: EDUSC, 2001.

PORTUGUEZ, Anderson Pereira. Turismo, Memória e Patrimônio Cultural. Roca, 2004.

RICHARDS, G. Turismo Cultural: padrões e implicações. In: CAMARGO, P.; CRUZ, G. da (eds) Turismo Cultural: Estratégias, sustentabilidade e tendências. UESC: Bahia, 2009.

SCHLÜTER, R. G. The Role of T-shirts in the Creation of Tourist Destination Images. Studies and Perspectives in Tourism Electronic Journal, nº1 Vol. 7. Buenos Aires, 1998.

\section{Sites Pesquisados}

http://www.argentina.travel/

http://www.colombia.travel/po/

WwW.mibuenosairesquerido.com

http://www.cuba-travel.tur.cu/es

http://www.senatur.gov.py/ 
http://www.turismochile.com/

http://www.cuba-travel.tur.cu/es

http://www.turismo-venezuela.com/

http://www.uruguai.org/

http://venezuela.turismo.travel/en

WWW.visitmexico.com 